\title{
Development of an Arthroscopically Compatible Polymer Additive Layer Manufacture Technique
}

Simon W Partridge ${ }^{1, *}$, Matthew J Benning ${ }^{1}$, Matthew J German ${ }^{2}$ and Kenneth W Dalgarno ${ }^{1}$.

${ }^{1}$ School of Mechanical and Systems Engineering, Newcastle University, Newcastle uponTyne, UK.

${ }^{2}$ Centre for Oral Health Research, School of Dental Sciences, Newcastle University, Newcastle upon Tyne, UK.

*Corresponding author: simon.partridge@ncl.ac.uk.

\section{Abstract}

This paper describes a proof of concept study designed to evaluate the potential for an in-vivo 3D printing route to support minimally invasive repair of the musculoskeletal system. The study uses a photocurable material to additively manufacture in-situ a model implant, and demonstrates that this can be achieved effectively within a clinically relevant timescale. The approach has the potential to be applied with a wide range of light curable materials, and with development could be applied to create functionally gradient structures in-vivo.

Keywords: 3d printing, arthroscope, additive manufacture, minimally invasive 


\section{Introduction}

The use of minimally invasive techniques for surgical interventions offers clear advantages to both the healthcare system and to the patient. ${ }^{1}$ Procedures are generally quicker, the degree of surgical insult is lower, which means that hospital stays and rehabilitation periods are shorter, which in turn offers a faster return to work and society for the patient. For the musculoskeletal system arthroscopic techniques are commonly used to enable examination, biopsy, debridement, and microfracture. In order to seek to repair the musculoskeletal system with minimal invasion, materials which can be injected into the body have been developed, notably cements for vertebroplasty and kyphoplasty procedures ${ }^{2}$, and polymeric or particulate bone defect filling materials. More recently there has been interest in the arthroscopic delivery of osteochondral plugs to treat small joint defects ${ }^{3,4}$, but this approach has not yet progressed to clinical adoption.

An alternative approach to bulk injection of a material is to use additive manufacturing to build up a 3D structure through the sequential formation and bonding of layers of material together. Previous work has shown that additive manufacture can, in principle, be used to fill joint defects ${ }^{5}$, but has not yet been explored how this could be achieved minimally invasively. This approach offers potential advantages over existing injectable approaches as it could extend the range of materials which could be processed using a minimally invasive approach, by allowing the use of materials which cure or set more effectively in small volumes. In addition, the approach could be used to develop multimaterial structures in order to provide a functionally gradient implant. 
A potential methodology for clinical application is outlined schematically in figure 1. Preparation of the implant site would involve removing damaged tissue and providing a lining to the defect to temporarily isolate the site whilst development of the implant took place. Sequential deposition and in-situ curing, in this case through blue light, of material would then be used to develop the implant through additive manufacture invivo. Visible light is non-thermogenic, less damaging to the cells and provides curing at higher depths in comparison to UV light ${ }^{6,7}$. Blue light curing is an attractive approach as it has been clinically applied widely in dentistry and with a higher depth penetration in comparison to violet light ${ }^{7-9}$.

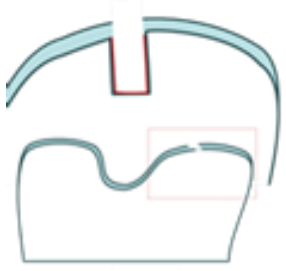

(a)

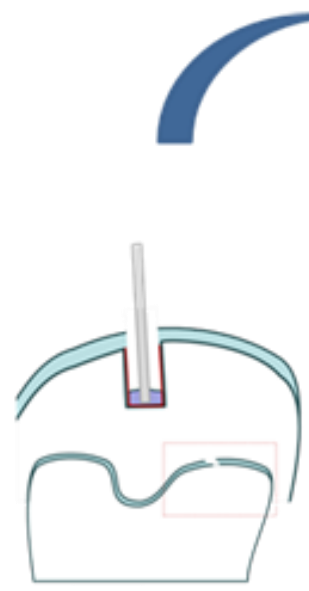

(b)

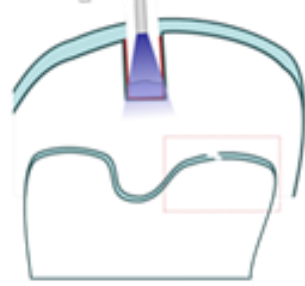

(c)

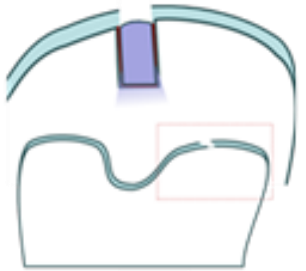

(d)

Figure 1 - Arthroscopic In-vivo Manufacture. Envisaged process is (a) preparation and isolation of the defect site; (b) deposition and (c) in-situ curing of material, repeated to fill defect $(d)$.

The work presented in this paper describes a proof of concept study undertaken to understand if a blue light curable material could be effectively delivered arthroscopically 
in order to fill a model osteochondral defect within a clinically useful timescale. HEMA (hydroxyethylmethacrylate) monomer was chosen as a model material for the study: it is a dental filler material with established blue light cure protocols, and well understood cure characteristics.

\section{Materials and Methods}

\subsection{Materials and Preparation}

Table 1 details the reagents used to create the HEMA solutions, and table 2 shows the constitution of the three solutions and the role of the different materials in the blue light cure system. Langer et al. $(1999)^{10}$ used a $1 \% \mathrm{w} / \mathrm{v} . \%$ in a 1:1 ratio of camphorquinone (CQ) to amine, however others such as Dewaele et al. $(2009)^{11}$ have used a $0.5 \mathrm{w} / \mathrm{v}$. \% 1:1 ratio. To determine whether the concentration of components in these systems work with the mono methyl ether hydroquinone (MEHQ) inhibited HEMA monomer the w/v. \% and ratio were investigated at these reported values. The solutions were prepared by weighing CQ and ethyl 4-(dimethylamino) benzoate (EDMAB) into an amber glass vial with black polytetrafluoroethylene (PTFE) faced rubber lined cap (fisher Scientific, 11309493). Using a pipette triethylene glycol dimethacrylate (TEGDMA) was then added until it constituted 0.5 mol\% of HEMA into the solution. The solution was then mixed for 1 hour using an SRT6 Stuart ${ }^{\circledR}$ tube roller (Bibby Scientific Ltd., Staffordshire, UK). 


\begin{tabular}{|c|c|c|c|c|c|}
\hline Chemical & Acronym & MEHQ & mol\% & $\begin{array}{c}\text { Product } \\
\text { number }\end{array}$ & Role \\
\hline 2-Hydroxyethylmethactylate & HEMA & $\leq 250$ & 97 & 128635 & Monomer \\
\hline $\begin{array}{c}\text { Camphorquinone } \\
\text { Ethyl 4-(dimethylamino) } \\
\text { benzoate }\end{array}$ & ED & 0 & - & 21325 & Photoinitiator \\
\hline $\begin{array}{c}\text { Triethylene glycol } \\
\text { dimethacrylate }\end{array}$ & TEGDMA & $\begin{array}{c}80- \\
120\end{array}$ & 95 & 261548 & Cross-linker \\
\hline
\end{tabular}

Table 1: Chemicals used for the formulation of photocurable HEMA solutions. All reagents purchased from Sigma Aldrich (Poole, UK).

\begin{tabular}{|c|c|c|c|c|}
\hline & HEMA Mol \% & $\begin{array}{c}\text { TEGDMA } \\
\text { mol/HEMA mol\% }\end{array}$ & $\begin{array}{c}\text { Camphorquinone } \\
\text { (w/v. \%) }\end{array}$ & $\begin{array}{c}\text { EDMAB } \\
\text { (w/v. \%) }\end{array}$ \\
\hline A & 96.5 & 0.5 & 1 & 1 \\
\hline B & 96.5 & 0.5 & 1 & 0.5 \\
\hline C & 96.5 & 0.5 & 0.5 & 1 \\
\hline
\end{tabular}

Table 2: Photocurable HEMA solutions compositions.

\subsection{Materials Processing}

\subsubsection{Light Source}

A Cree $^{\circledR}$ XLamp $^{\circledR}$ XP-E LED (royal blue) 450-465 nm (Cree Inc., North Carolina, USA) was used with an optical PMMA LED lens (LEDiL, FP11085, Salo, Finland). Power was supplied by a British Standards Tester PSM 3/2A 3 channel regulated DC power supply (BSIgroup, London, UK). The radius of the illumination spot was measured as $0.5 \mathrm{~cm}$ when it was $1 \mathrm{~cm}$ from the lens, and the LED was operated at $734 \mathrm{~mA}$, which gave an estimated power output of $1000 \mathrm{~mW} / \mathrm{cm}^{2}$. 


\subsubsection{Mould and Photocuring Chamber}

A two-part PTFE mould was fabricated to provide an array of model defects. The top part of the PTFE mould consisted of an array of nine holes $8 \mathrm{~mm}$ in diameter with a 2 $\mathrm{mm}$ deep couterbore of $40 \mathrm{~mm}$ diameter cut to act as a location feature for the photocuring chamber. The base part of the PFTE mould consisted of an array of pins 8 $\mathrm{mm}$ in diameter aligned to fit into the holes in the top part. Upon assembly, the wells were $8 \mathrm{~mm}$ in diameter with $6 \mathrm{~mm}$ depth (figure 1), chosen to be representative of small osteochondral defects.
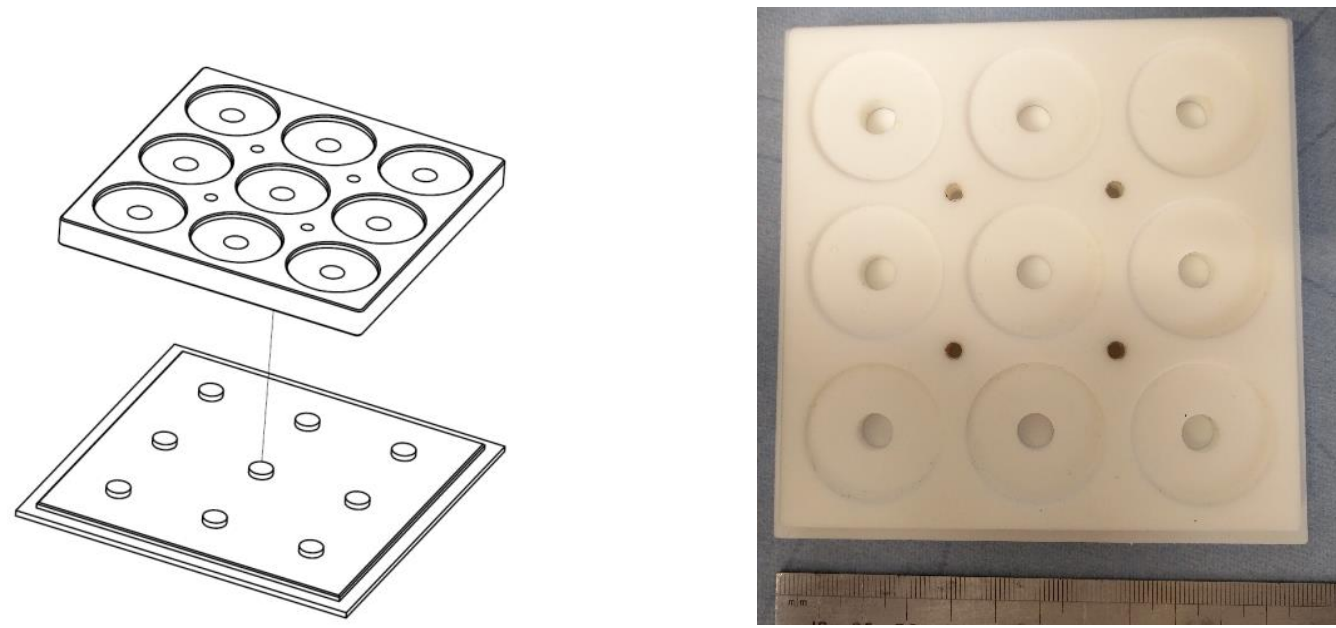

Figure 1: Schematic diagram of the PTFE mould assembly (left) and image of the assembled PTFE mould (right).

The photocuring chamber consisted of a closed 3D printed PLA cylinder of $40 \mathrm{~mm}$ diameter with a central $3 \mathrm{~mm}$ hole for connecting the LED holder and a $5 \mathrm{~mm}$ hole for the wires and nitrogen inlet (figure 2). The PMMA LED lens was mounted to the XP-LED and attached to an aluminium column with Artic Silver ${ }^{\circledR} 5$ thermal paste (Visalia, CA, USA). 
A

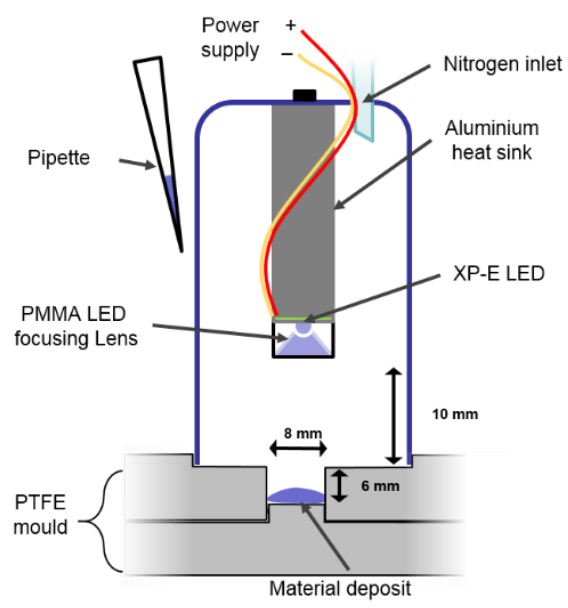

B

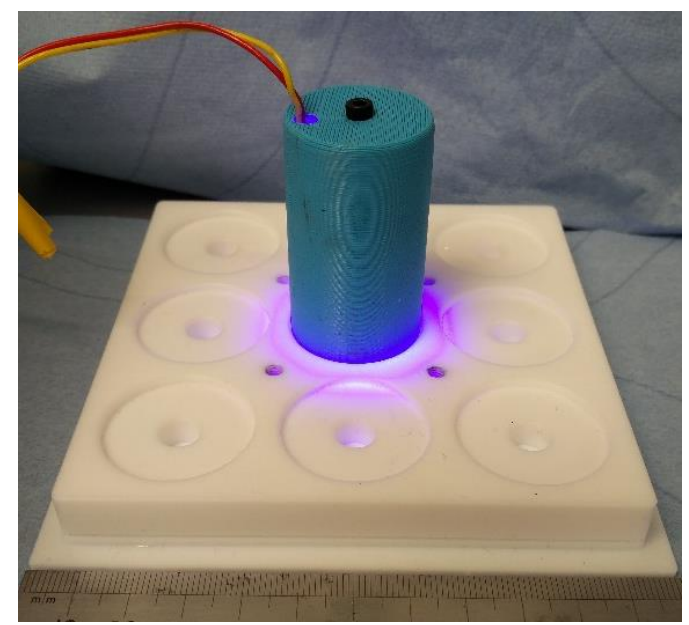

Figure 2: A) Schematic of the photocuring chamber and PTFE mould cross-section. B) Image example, full assembly of the photocuring chamber (without nitrogen tube) positioned on the PTFE mould.

\subsubsection{HEMA Polymerisation}

The photochemical process of polymerisation depends on the transfer of reactive species generated by the photoinitiator CQ in response to blue light. The transfer of this reactive species from the CQ to the HEMA monomer is facilitated by the tertiary amide EDMAB and leads to propagation of the polymer chain. The presence of oxygen within this system absorbs the reactive species and thus retards initiation and propagation of the reaction ${ }^{12}$. In these experiments nitrogen gas was used to displace oxygen from the curing chamber to diminish oxygen inhibition of the photocuring process.

The intrinsic and extrinsic factors affecting curing efficiency are explained in detail in Leprince et al. (2013) $)^{12}$. In terms of the exposure time the key factors include the formulation, volume, temperature and irradiance intensity. Ambient temperature was controlled by an air conditioning unit at $20^{\circ} \mathrm{C}$. 
In previous studies of blue light cure a range of blue light intensities have been used, ranging from $1-3000 \mathrm{~mW} / \mathrm{cm}^{2}$ 13,12. The materials used in this study include the MEHQ inhibitor, which is added to dental formulations to provide shelf life. In order to ensure that the processing conditions would mitigate MEHQ inhibition, a relatively high light intensity of $1000 \mathrm{~mW} / \mathrm{cm}^{2}$ was used.

The $10 \mathrm{~mm}$ distance of the LED to the maximal curing base was selected as this illuminated the build area effectively. From initial experiments, $\sim 1 \mathrm{~mm}$ HEMA layers cured into a malleable disc with 1 minute exposure time, ergo controlled prolonged exposure time points were investigated.

To produce $\sim 1 \mathrm{~mm}$ thick layers $50 \mu \mathrm{L}$ of the HEMA solution was pipetted into a PTFE mould. The photocuring chamber with flowing nitrogen was then placed over the well as shown in figure 2 and the power supply activated to deliver $734 \mathrm{~mA}$ equating to 1000 $\mathrm{mW} / \mathrm{cm}^{2}$ at the spot $10 \mathrm{~mm}$ from the lens. Therefore, HEMA exposure times were investigated between 1 and 10 minutes.

For multi-layered experiments this process was repeated, with no delay between the end of an exposure and the deposition of the material for the next layer, using formulation $\mathrm{A}, 734 \mathrm{~mA}$, and an exposure time of 1 minute.

\subsection{Material Characterisation}

\subsubsection{Fourier Transformed Infrared Spectroscopy (FTIR)}

Solid material samples were analysed using an ATR-FTIR Perkin Elmer Spectrum 100 with PerkinElmer's Spectrum ${ }^{\mathrm{TM}}$ v6 FT-IR software. Spectra were collected by cleaning the diamond/ZnSe crystal surface with acetone or $100 \%$ ethanol before and after use. The 
machine was calibrated to background atmosphere prior to data collection. The base of the polymerised HEMA (polyHEMA) samples were then loaded onto the diamond/ZnSe ATR crystal detection area and locked in place using the pressure arm. All samples were polished using graded abrasive paper to ensure sufficient contact with the ATR crystal. Spectra were then recorded from $4000 \mathrm{~cm}^{-1}$ to $650 \mathrm{~cm}^{-1}$ with a resolution of $4 \mathrm{~cm}^{-1}$ and a minimum of 32 scans per sample.

The multi-layered samples were bisected using a circular diamond blade. The samples were also polished to ensure contact with the ATR crystal. Measurements were taken centrally at the top and bottom of the samples (figure 3), with the ATR crystal adjacent to the top and bottom surfaces, and centrally in the middle of the samples halfway between the top and bottom measurements.

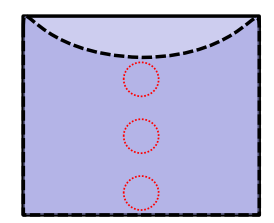

Figure 3: Positioning of the ATR-FTIR detection crystal (red) on cross-sectioned polyHEMA cylinders (blue)

The degree of conversion (DC) was calculated by comparing the vibrational band of the residual non-polymerised methacrylate $\mathrm{C}=\mathrm{C}$ stretching mode at $1638 \mathrm{~cm}^{-1}$ to the aromatic C-C stretching mode at $1710 \mathrm{~cm}^{-1}$ used as an internal standard. The nonpolymerised HEMA solution was used as a reference. 


\subsubsection{Imaging}

The sectioned polyHEMA cylinders were imaged using a Leica M165FC with integrated LED spotlights. Images were acquired and processed using DFC310 FX camera Leica with the Application Suite (LAS) software (Leica Microsystems Heidelberg GMBH Germany).

Superficial heating of the sectioned polyHEMA cylinders was applied using $100^{\circ} \mathrm{C}$ hot air supplied by a TENMA 21-10125 rework station (Tokyo, Japan). The hot air gun was positioned approximately $1 \mathrm{~cm}$ from the sample surface and held for 10-20 seconds.

\subsubsection{Dimensional Measurements}

The samples were measured using Mitutoyo digimatic calipers 0-150 mm (Mitutoyo, Sakado, Japan).

\subsubsection{Compression Test}

Six layer polyHEMA cylinders were tested in compression using a H25KS Tinius Olsen Ltd. (Surrey, UK) testing machine with a $25 \mathrm{kN}$ load cell. The cylinders were initially trimmed at each end to create parallel surfaces. The crosshead speed was $2 \mathrm{~mm} /$ minute and samples were tested to failure.

\subsection{Statistical Methods}

Collected data were processed and formatted using Microsoft Excel 2016. Statistical data analysis was performed using GraphPad Prism $6^{\circledR}$. One-way analysis of variance (ANOVA) were performed using a Tukey's HSD post-hoc test, two-way ANOVAs were performed when possible to determine variation between data sets. 


\section{Results}

\subsection{Curing of Single Layers}

\subsubsection{Morphology}

Figure 4 shows the polyHEMA discs from formulations $A-C$ with 1 and 4 minutes exposure times. After 1 minute exposure the polyHEMA discs from formulations $A$ and C have strong yellow colour. The discs all had a meniscus, with some material failing to cover the PTFE mould surface (denoted by the arrows in figure 4A). Figure 4B shows that apart from those samples where material coverage was incomplete the diameter of the samples was consistent and not significantly affected by exposure time.

\subsection{FTIR and Degree of Conversion}

Figure $5 A$ shows the ATR-FTIR spectra from single layer specimens of formulation A following exposure for 1-10 minutes, indicating that 1 minute of exposure was sufficient for the radical polymerisation reaction to take place. Results from figure $5 \mathrm{~B}$ indicate no significant differences between the degree of conversion of HEMA monomer from the different formulations across all of the exposure times. 


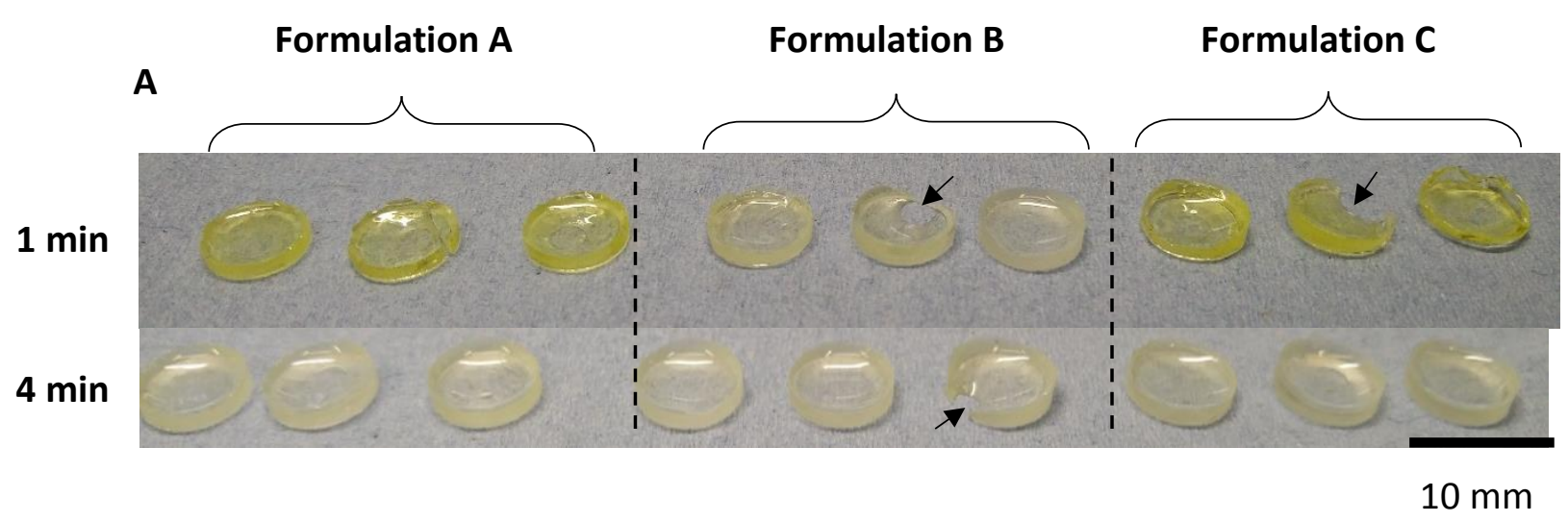

B

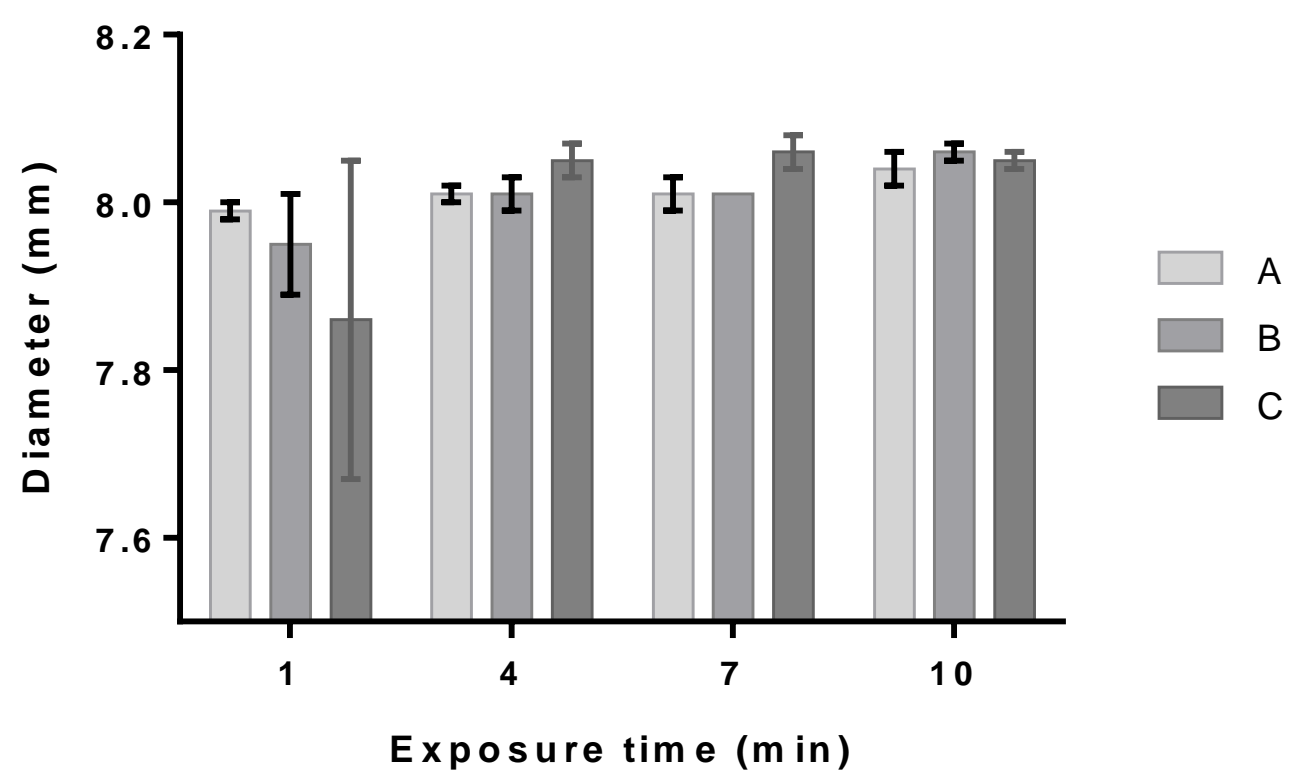

Figure 4: A) images of polyHEMA discs from formulations A-C following photopolymerisation with 1 and 4 minutes exposure (10 mm scale bar). Arrows denote incomplete coverage of mould surface B) Diameter of polyHEMA discs. Bars shows the mean \pm the standard deviation. 
A

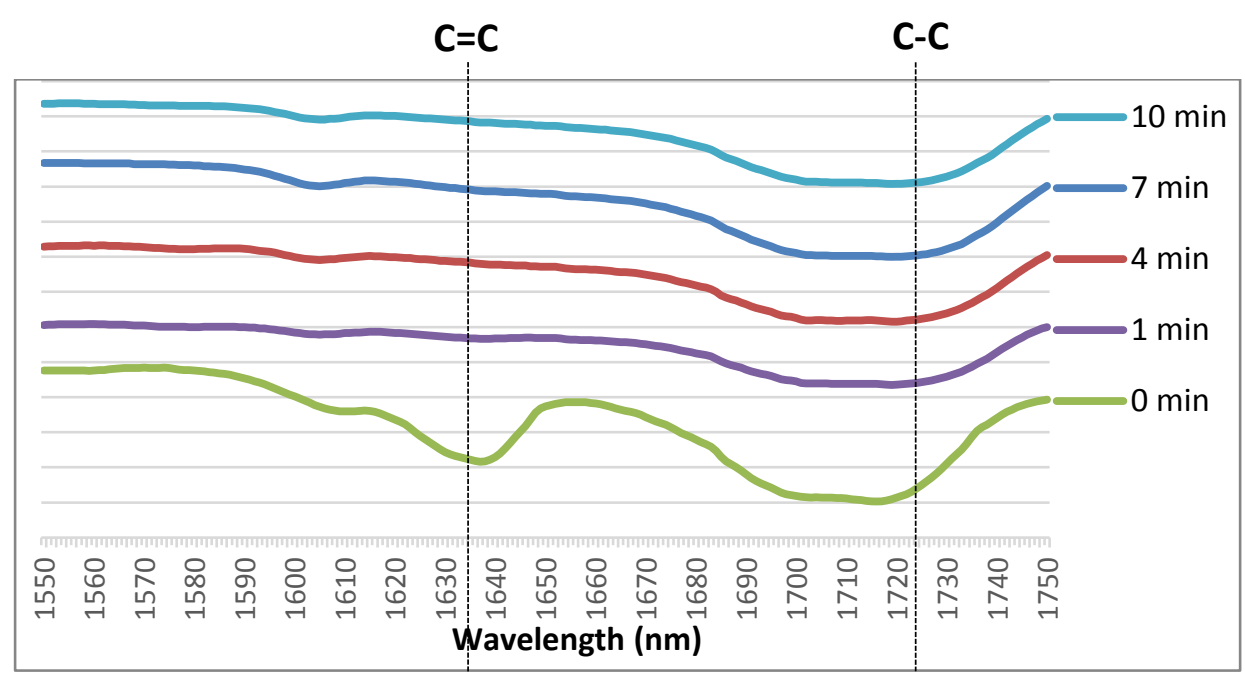

B

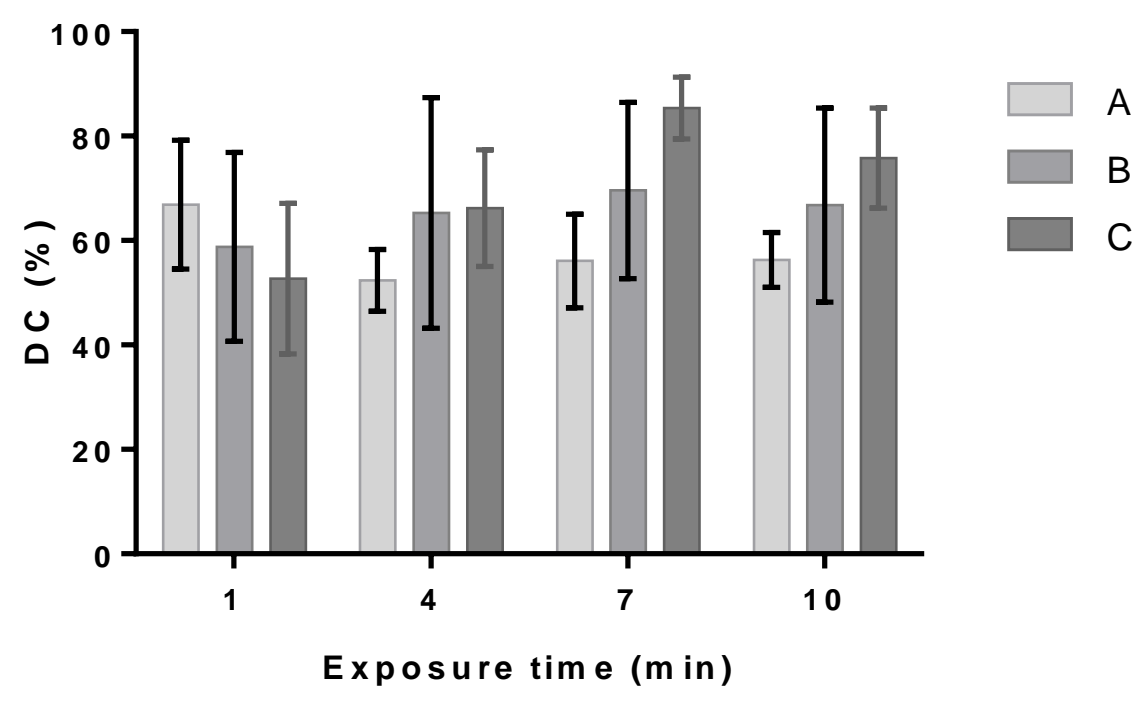

Figure 5: A) ATR-FTIR spectra of formulation A before and after 1 minute exposure. Narrow scan from $1550-1800 \mathrm{~cm}^{-1}$ showing aliphatic C-C $\left(1710 \mathrm{~cm}^{-1}\right)$ and aromatic $\mathrm{C}=\mathrm{C}\left(1638 \mathrm{~cm}^{-1}\right)$ vibrational modes. B) The degree of HEMA monomer conversion from formulations A-C. The bars represent the mean \pm the standard deviation $(n=3)$. 


\subsection{Multiple layer curing}

\subsection{Morphology}

Figure $6 \mathrm{~A}$ shows that the multi-layer polyHEMA cylinders retained the meniscus throughout the addition of further layers. Superficial heating of the cut surface of the polyHEMA plugs revealed curved lined features correlating to the layer interfaces (figure $6 B)$.

Figure $6 \mathrm{C}$ shows that the cylinders were broadly consistent in diameter, although the single layer specimens were on average around $2 \%$ smaller in diameter than the multilayer specimens. The sequential weight gains were broadly as would be expected, as were most of the height gains, apart from layers 4 and 5 where some levelling out of the meniscus seems to occur. Note that the height of layer 1 is misleading: in all cases the height measurement was to the top of the meniscus.

\subsection{Degree of Conversion}

Figure 7 (left) shows ATR-FTIR analysis of the base layer degree of conversion following sequential layer addition, and indicates no significant difference in degree of conversion of the polymer on the base layer for samples of different heights. In addition, ATR-FTIR of the cross-sectioned samples, figure 7 (right), shows that the degree of conversion through the layers remained consistent throughout, with no significant differences in DC. 


\subsection{Mechanical Properties}

Compression testing with 6-layer samples gave an average modulus of $204 \mathrm{MPa}$ (min $184 \mathrm{MPa}$, max $240 \mathrm{MPa}$ ), and an average compressive strength of $82 \mathrm{MPa}$ (min $69 \mathrm{MPa}$, $\max 92 \mathrm{MPa})$. 


\section{A}

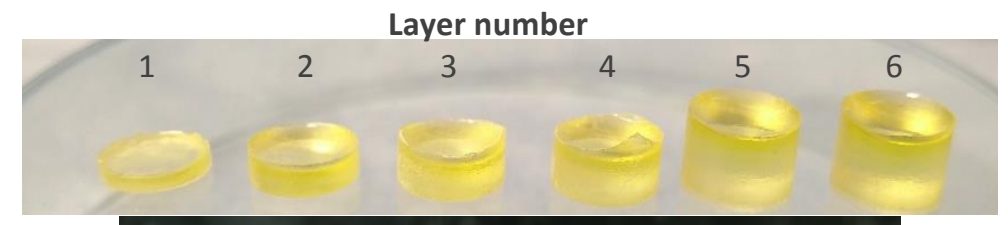

B

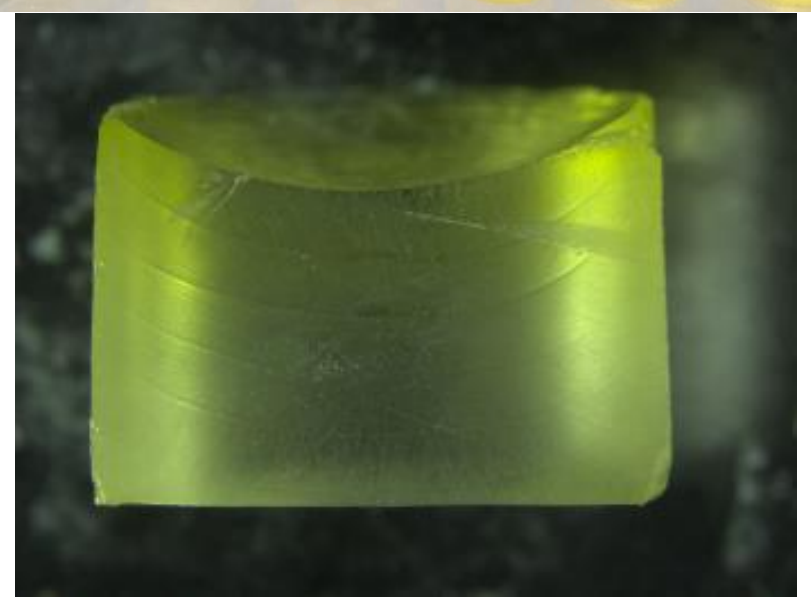

C

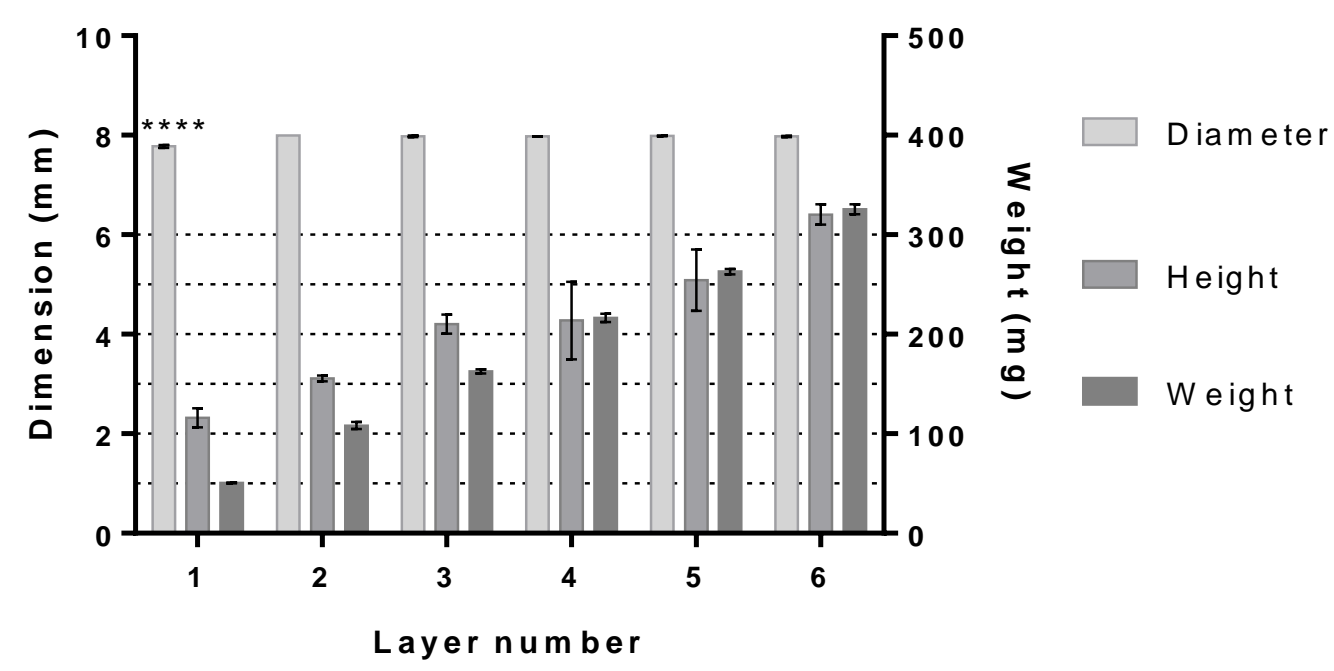

Figure 6: A) Images of polyHEMA cylinders with 1 - 6 layers (10 mm scale bar). B) Stereomicroscope images of sectioned 6-layer polyHEMA cylinders following superficial heat treatment. C) Average diameter, edge height and weight of polyHEMA cylinders per layer. Dashed grid represents expected values per layer. Bars shows the mean \pm the standard deviation $(n=3)$. 


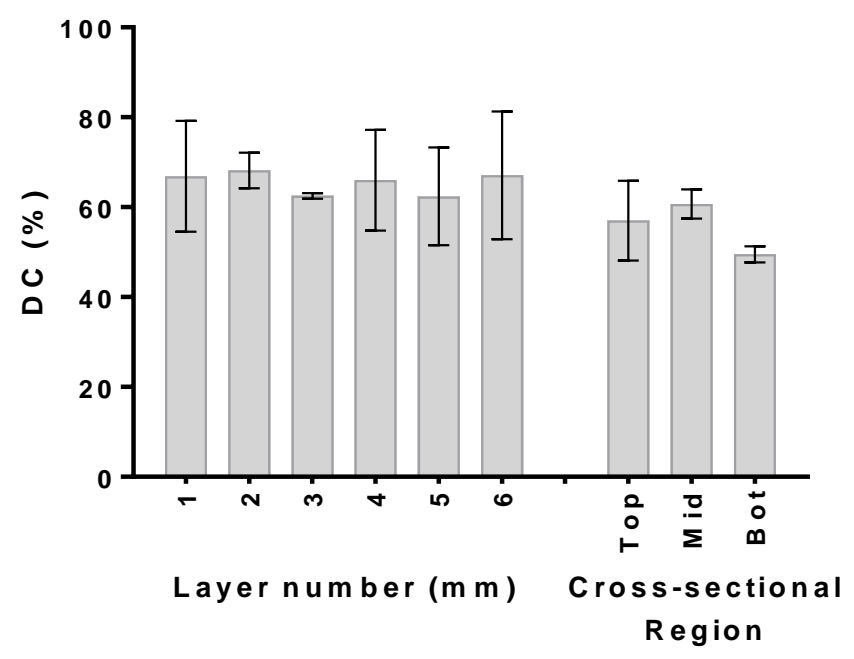

Figure 7: Base layer DC following sequential layer-by-layer exposure (left) and cross-sectional DC within the polyHEMA cylinders (right). Bars show the mean \pm the standard deviation $(n=3)$.

\section{Discussion}

\subsection{Effectiveness of the Processing Route in Curing HEMA}

The curing of single layers resulted in some incomplete surface coverage, which remained inconsistent. This was most likely caused by poor wettability of the HEMA mixture on the PTFE substrate. However, the single layer experiments were valuable in showing that the 1 minute exposure time was sufficient to stimulate polymerisation of composition A. The sequential layer photopolymerisation processing route produced solid, robust polyHEMA cylinders which filled the model defects, with 6-layer cylinders produced in less than 10 minutes. The average degree of conversion for the multi-layer specimens was between $50 \%$ and $60 \%$. The degree of conversion achieved was typical of blue light cured methacrylate based dental filler materials (for example Galvao et al. 
$(2013)^{14}$ quote $55 \%$ for PMMA processed using conventional dental curing equipment; and Marovic et al. $(2013)^{15}$ quote around $60 \%$ for a range of methacrylate based materials), so the processing route is considered to have achieved a DC broadly equivalent to that achieved in commercial light cured materials. We consider that a useful volume of material could be delivered and polymerised in-situ at a rate which is clinically practical, and so the approach is considered to have clinical promise.

\subsection{Potential for Clinical Application}

HEMA was used within this study as a model material with which to perform the proof of concept study - it does not have the biological properties for clinical application in a musculoskeletal application. In order for the approach to be viable for an orthopaedic application, the process would require the use of materials which would have in-vivo properties relevant to the musculoskeletal system. However, there is a significant body of work on photocurable materials which could have clinical application. Table 3 summarises materials which have potential to be applied to the musculoskeletal system using the arthroscopic approach outlined in this paper, and includes modified HEMA systems which could have potential alongside a range of other materials. For the most part these materials are not yet commercially available, but there is clear potential for an approach like the one outlined in this paper to be adopted for their use. Indeed several photocurable monomer systems have been used in additive manufacturing of cell - hydrogel constructs outlined in an excellent review by Melchels et al (2012) ${ }^{16}$. Whilst the light curing kinetics will vary from material system to material system the rate at which the model plugs could be made within the proof of concept study gives confidence that delivery and cure in-situ of a wider range of materials within clinically relevant timescales will be possible. There is also the potential to reinforce the polymers 
with a nano-scale bioceramic, and with an appropriate material delivery system functionally gradient composites could be created. The overall material system could be inert and biocompatible, designed to stay as deposited, or bioactive, designed to resorb over time and be replaced with natural tissue, and table 3 identifies both inert and bioactive materials. 


\begin{tabular}{|c|c|c|c|}
\hline Category & Material/Reference & Targeted tissue & Comments \\
\hline \multirow{11}{*}{$\begin{array}{l}\text { Synthetic } \\
\text { polymers }\end{array}$} & Polyurethanes ${ }^{17}$ & Soft tissue & $\begin{array}{l}\text { Polyurethane incorporating hydrolysable soft segments such as PCL or polypropylene glycol: } \\
\text { In-vivo tested }-6 \mathrm{~mm} \times 2 \mathrm{~mm} \text { cylindrical discs subcutaneous implantation Wistar rats. } \\
\text { In-vivo tested }-1 \mathrm{~mL} \text { injected intramuscular injection dorsum Wistar rats. }\end{array}$ \\
\hline & Polylactic acid (PLA) ${ }^{18,18}$ & $\begin{array}{l}\text { Hard/ soft tissue } \\
\text { Bone and heart }\end{array}$ & $\begin{array}{l}\text { Ethylene glycol - lactic acid oligomer (2EG10LA): Critical size defect model Sprague-Dawley rats } 8 \mathrm{~mm} \text { defect } \\
\text { Poly(TMC-DLLA): In-vitro assessment cardiomyocytes. }\end{array}$ \\
\hline & Polyhydroxyalkanoates $(\mathrm{PHB})^{19}$ & Hard/ soft tissue & PHB-co-hydroxyvalerate and HEMA membranes: No in-vitro cell/ in-vivo testing \\
\hline & Polyethers ${ }^{20}$ & Soft tissue & $\begin{array}{l}\text { A number of polyethers such as poly(ethylene glycol) (PEG) are used to as part of oligomers and triblock copolymers. PCL-b-PEG-b-PCL: } \\
\text { In-vitro assessment for adherence of fibroblasts. }\end{array}$ \\
\hline & Polycaprolactone $(\mathrm{PCL})^{17,21,22}$ & Soft tissue & Poly(-caprolactone-co-trimethylene carbonate): In-vitro assessment of endothelial cells and cardiomyocytes. \\
\hline & Poly(propylene fumarate) (PPF) ${ }^{23,24}$ & $\begin{array}{l}\text { Hard tissue } \\
\text { Bone }\end{array}$ & $\begin{array}{l}\text { PFF: 3D printed structures assessed for } 112 \text { days in-vitro with fibroblasts } \\
\text { PFF/HEMA/Bioglass: } 2 \mathrm{D} \text { in-vitro assessment using human malignant melanoma cells. Bone adhesion mechanical tests. }\end{array}$ \\
\hline & $\begin{array}{l}\text { poly(trimethylene carbonate) } \\
\text { (TMC) }\end{array}$ & $\begin{array}{l}\text { Soft tissue } \\
\text { Cartilage }\end{array}$ & $\begin{array}{l}\text { PEG-TMC and TMC-PCL-TMC: Fused filament fabricated 3D scaffolds assessed in-vitro with patient derived human mesenchymal stem cells (MSC). } \\
\text { Enzymatic in-vitro degradation assay. } \\
\text { Poly(TMC-DLLA): In-vitro assessment cardiomyocytes. }\end{array}$ \\
\hline & Polyphosphoesters (PPE) $)^{26}$ & $\begin{array}{l}\text { Hard/ soft tissue } \\
\text { Bone }\end{array}$ & $\begin{array}{l}\text { Poly(6-aminohexyl propylene phosphate) (PPE) modified with acylated PEG (PPE-PEG): In-vitro: MSC 90\%+ viability to monomer (max } 10 \mathrm{mg} / \mathrm{mL} \text { ). MSC } \\
\text { encapsulated in } 8 \mathrm{~mm} \text { diameter cylinders with } 150 \mu \mathrm{L} \text { monomer solution ( } 3 \mathrm{~mm} \text { height). }\end{array}$ \\
\hline & Polyanhydrides ${ }^{10,27}$ & $\begin{array}{l}\text { Hard/ soft tissue } \\
\text { Bone }\end{array}$ & $\begin{array}{l}\text { Poly(sebacic anhydride): In-vivo tested ( } 4 \text { days)- material was filled into } 2 \mathrm{~mm} \text { drilled tibia defect in Sprague-Dawley rats. New collagen and blood } \\
\text { vessel formation observed around the implant site. } \\
\text { Hydroxyaptite nanoparticle filled polyanhydride - no in-vitro cell/ in-vivo testing. }\end{array}$ \\
\hline & polyHEMA ${ }^{28,29}$ & Soft tissue & $\begin{array}{l}\text { HEMA and diethylene glycol dimethacrylate: No in-vitro study. } \\
\text { HEMA grafted with polyamidoamine: In-vitro assessment encapsulating human MSC in a } 1 \mathrm{~cm} \text { diameter } 3 \mathrm{~mm} \text { height. }\end{array}$ \\
\hline & Triblock polymers ${ }^{20}$ & Hard/ soft tissue & PLA-b-PCL- $b$-PLA, PGA-b-PCL- $b$-PGA, PCL-b-PEO- $b$-PCL: In-vitro assessments Cell attachment study (2004). \\
\hline \multirow{6}{*}{$\begin{array}{l}\text { Natural } \\
\text { polymers }\end{array}$} & Alginate $^{30}$ & Soft tissue & Alginate methacrylate: No in-vitro assessment. \\
\hline & Hyaluronic acid ${ }^{30,31}$ & Soft tissue & Hyaluronan methacrylate: No in-vitro assessment. \\
\hline & Gelatin $^{32,33,34,35}$ & Soft tissue & $\begin{array}{l}\text { Gelatin methacrylate (GelMA): } \\
\text { In-vitro:5 mm diameter cylinder with } 2 \mathrm{~mm} \text { thickness) } \\
\text { in-vivo: } \mathrm{C} 57 \mathrm{BL} / 6 \mathrm{~J} \text { mice } 1 \mathrm{~mL} \text { injected subcutaneously. }\end{array}$ \\
\hline & Pullulan $^{36}$ & Soft tissue & Pullulan methacrylate. In-vitro assessment: Encapsulation of NIH 3Т3 fibroblasts, HepG2 liver cells and endothelial cells assessed for viability. \\
\hline & Gellan-gum ${ }^{37}$ & $\begin{array}{l}\text { Soft/ hard tissue } \\
\text { Bone }\end{array}$ & $\begin{array}{l}\text { Gellan-gum methacrylate: In-vitro assessment: Adipose derived stem cells encapsulated and assessed using hydrogel on-chip process. Demonstrated } \\
\text { in-vitro spontaneous differentiation into the osteogenic lineage. }\end{array}$ \\
\hline & Chitosan ${ }^{7}$ & Soft tissue & $\begin{array}{l}\text { Methacrylated glycol chitosan. } \\
\text { In-vitro assessment: Viability study using chondrocytes - investigated formulation cytotoxicity and influence of irradiation on encapsulated cells. } \\
\text { In-vivo assessment: Osteochondral defect explant model - } 4 \mathrm{~mm} \text { diameter in New Zealand white rabbit's knees cultured for } 14 \text { days. }\end{array}$ \\
\hline
\end{tabular}

Table 3: Summary of potential injectable photocurable biomaterials for bone and cartilage repair. 
For a range of reasons, we consider that the use of a membrane to isolate the volume within the body where the plug would be delivered would be required. This would avoid the ingress of blood into the build volume, and would mean that monomers would not leach into the surrounding tissue prior to being polymerised. As a result of the feasibility study a third reason can be identified: the membrane and implant materials should be chosen to avoid the formation of a meniscus. Meniscus formation is controlled by the wettability of the wall material by the contained liquid, and so engineering the surface properties of the membrane offers a way of controlling the overall shape of the implant. The choice of membrane material would clearly also depend upon whether an inert or bioactive implant was being developed. For an inert material a poly(methyl methacrylate) membrane would offer good levels of biocompatibility, whereas for a bioactive implant there are a range of possible membranes to support tissue regeneration ${ }^{38}$.

\section{Conclusions}

In-vivo additive manufacture using a minimally invasive approach offers an attractive route to the production of implants for the musculoskeletal system, and we have demonstrated proof of principle for a system based on light curable biomaterials. A simple model system has been developed in order to build plugs of appropriate dimensions suitable for chemical and mechanical characterisation. HEMA, used as a model material, demonstrated that appropriate volumes of material could be delivered within clinically relevant timescales and effectively polymerised in-situ, with minimal influence of the sequential layer manufacture process on the degree of conversion. A wide range of light curable biomaterials, with potential for application across the musculoskeletal system using this processing route, are being developed. 


\section{Acknowledgments}

This work reported in this paper was funded by the EPSRC Centre for Innovative Manufacture in Medical Devices (MeDe Innovation; EP/K029592).

\section{References}

1. Bonutti, P. M., Mont, M. A., Mcmahon, M., Ragland, P. S. \& Kester, M. Minimally Invasive Total Knee Arthroplasty. J. Bone Joint Surg. Am. 86-A Suppl, 26-32 (2005).

2. Burton, A. W., Rhines, L. D. \& Mendel, E. Vertebroplasty and kyphoplasty: a comprehensive review. Neurosurg. Focus 18, e1 (2005).

3. Cross, L. M., Thakur, A., Jalili, N. A., Detamore, M. \& Gaharwar, A. K. Nanoengineered biomaterials for repair and regeneration of orthopedic tissue interfaces. Acta Biomater. 42, 2-17 (2016).

4. Spector, M. \& Lim, T. C. Injectable biomaterials: a perspective on the next wave of injectable therapeutics. Biomed. Mater. 11, 14110 (2016).

5. Cohen, D. L., Lipton, J. I., Bonassar, L. J. \& Lipson, H. Additive manufacturing for in situ repair of osteochondral defects. Biofabrication 2, 35004 (2010).

6. Wong, D. Y., Ranganath, T. \& Kasko, A. M. Low-dose, long-wave UV light does not affect gene expression of human mesenchymal stem cells. PLoS One 10, 1-21 (2015).

7. $\mathrm{Hu}, \mathrm{J}$. et al. Visible light crosslinkable chitosan hydrogels for tissue engineering. 
Acta Biomater. 8, 1730-1738 (2012).

8. Harlow, J. E., Rueggeberg, F. A., Labrie, D., Sullivan, B. \& Price, R. B. Transmission of Violet and Blue Light Through Conventional (layered) and Bulk Cured ResinBased Composites. J. Dent. (2016). doi:10.1016/j.jdent.2016.06.007

9. Temenoff, J. S. \& Mikos, a G. Injectable biodegradable materials for orthopedic tissue engineering. Biomaterials 21, 2405-2412 (2000).

10. Anseth, K. S., Shastri, V. R. \& Langer, R. Photopolymerizable degradable polyanhydrides with osteocompatibility. Nat. Biotechnol. 17, 156-159 (1999).

11. Dewaele, M. et al. Influence of curing protocol on selected properties of lightcuring polymers: Degree of conversion, volume contraction, elastic modulus, and glass transition temperature. Dent. Mater. 25, 1576-1584 (2009).

12. Leprince, J. G., Palin, W. M., Hadis, M. A., Devaux, J. \& Leloup, G. Progress in dimethacrylate-based dental composite technology and curing efficiency. Dent. Mater. 29, 139-156 (2013).

13. Cook, W. D. Photopolymerization kinetics of dimethacrylates using the camphorquinone/amine initiator system. Polymer (Guildf). 33, 600-609 (1992).

14. Galvão, M. R., Caldas, S. G. F. R., Bagnato, V. S., Rastelli, A. N. de S. \& de Andrade, M. F. Evaluation of degree of conversion and hardness of dental composites photoactivated with different light guide tips. Eur. J. Dent. 7, 86-93 (2013).

15. Marovic, D. et al. Degree of conversion and microhardness of dental composite resin materials. in Journal of Molecular Structure 1044, 299-302 (2013). 
16. Melchels, F. P. W. et al. Additive manufacturing of tissues and organs. Prog. Polym. Sci. 37, 1079-1104 (2012).

17. Pereira, I. H. L. et al. Photopolymerizable and injectable polyurethanes for biomedical applications: Synthesis and biocompatibility. Acta Biomater. 6, 30563066 (2010).

18. Burdick, J. A., Philpott, L. M. \& Anseth, K. S. Synthesis and characterization of tetrafunctional lactic acid oligomers: A potential in situ forming degradable orthopaedic biomaterial. J. Polym. Sci. Part A Polym. Chem. 39, 683-692 (2001).

19. Gursel, I. et al. Synthesis and mechanical properties of interpenetrating networks of polyhydroxybutyrate-co-hydroxyvalerate and polyhydroxyethyl methacrylate. Biomaterials 19, 1137-1143 (1998).

20. Chan-Park, M. B., Zhu, A. P., Shen, J. Y. \& Fan, A. L. Novel photopolymerizable biodegradable triblock polymers for tissue engineering scaffolds: Synthesis and characterization. Macromol. Biosci. 4, 665-673 (2004).

21. Grijpma, D. W., Melchels, F. P. W., Hou, Q. \& Feijen, J. MethacrylateFunctionalized Oligomers Based On Lactide, E- Caprolactone And Trimethylene Carbonate For Application In Stereo-Lithography. Mater. Res. Innov. Online 321330 (2006). doi:10.1179/mri.2006.10.3.321

22. Pêgo, A. P. et al. Preparation of degradable porous structures based on 1,3trimethylene carbonate and D,L-lactide (co)polymers for heart tissue engineering. Tissue Eng. 9, 981-94 (2003). 
23. He, S. et al. Synthesis of biodegradable poly(propylene fumarate) networks with poly(propylene fumarate)-diacrylate macromers as crosslinking agents and characterization of their degradation products. Polymer (Guildf). 42, 1251-1260 (2001).

24. Wang, M. O., Piard, C. M., Melchiorri, A., Dreher, M. L. \& Fisher, J. P. Evaluating changes in structure and cytotoxicity during in vitro degradation of threedimensional printed scaffolds. Tissue Eng. Part A 21, 1642-53 (2015).

25. Bat, E. et al. Ultraviolet light crosslinking of poly(trimethylene carbonate) for elastomeric tissue engineering scaffolds. Biomaterials 31, 8696-8705 (2010).

26. Li, Q. et al. Biodegradable and photocrosslinkable polyphosphoester hydrogel. Biomaterials 27, 1027-1034 (2006).

27. Li, H., Chen, Y. \& Xie, Y. Photo-crosslinking polymerization to prepare polyanhydride/needle-like hydroxyapatite biodegradable nanocomposite for orthopedic application. Mater. Lett. 57, 2848-2854 (2003).

28. Kumar, D. et al. Three-dimensional hypoxic culture of human mesenchymal stem cells encapsulated in a photocurable, biodegradable polymer hydrogel: A potential injectable cellular product for nucleus pulposus regeneration. Acta Biomater. 10, 3463-3474 (2014).

29. Lu, S. \& Anseth, K. S. Photopolymerization of multilaminated poly(HEMA) hydrogels for controlled release. J. Control. Release 57, 291-300 (1999).

30. Smeds, K. A. \& Grinstaff, M. W. Photocrosslinkable polysaccharides for in situ 
hydrogel formation. J. Biomed. Mater. Res. 54, 115-121 (2001).

31. Fenn, S. L. \& Oldinski, R. A. Visible light crosslinking of methacrylated hyaluronan hydrogels for injectable tissue repair. J. Biomed. Mater. Res. - Part B Appl. Biomater. 104, 1229-1236 (2016).

32. Loessner, D. et al. Functionalization, preparation and use of cell-laden gelatin methacryloyl-based hydrogels as modular tissue culture platforms. Nat. Protoc. 11, 727-46 (2016).

33. Klotz, B. J., Gawlitta, D., Rosenberg, A. J. W. P., Malda, J. \& Melchels, F. P. W. Gelatin-Methacryloyl Hydrogels: Towards Biofabrication-Based Tissue Repair. Trends Biotechnol. 34, 394-407 (2016).

34. Jia, W. et al. Direct 3D bioprinting of perfusable vascular constructs using a blend bioink. Biomaterials 106, 58-68 (2016).

35. Koshy, S. T., Ferrante, T. C., Lewin, S. A. \& Mooney, D. J. Injectable, porous, and cell-responsive gelatin cryogels. Biomaterials 35, 2477-2487 (2014).

36. Hughes, l. et al. Otopetrin 1 is required for otolith formation in the zebrafish Danio rerio. Dev. Biol. 276, 391-402 (2004).

37. Oliveira, M. B., Custódio, C. A., Gasperini, L., Reis, R. L. \& Mano, J. F. Autonomous osteogenic differentiation of hASCs encapsulated in methacrylated gellan-gum hydrogels. Acta Biomater. 41, 119-132 (2016).

38. Gentile, P., Chiono, V., Tonda-Turo, C., Ferreira, A. M. \& Ciardelli, G. Polymeric membranes for guided bone regeneration. Biotechnol. J. 6, 1187-1197 (2011). 